\title{
PENGARUH KUALITAS WEBSITE TERHADAP KEPUTUSAN PEMBELIAN LAYANAN PEMESANAN KAMAR HOTEL PADA SITUS TRAVELOKA
}

\author{
Yenli Megawati ${ }^{1}$, \\ 1) Program Studi Manajemen, Universitas Bunda Mulia \\ 9 November 2018
}

\begin{abstract}
The development of technology including the internet is increasingly fast and has an impact on changes in business patterns and consumer behavior especially online consumber behavior. One business that is increasingly today is hotel room booking services through various online sites. There are many online companies that offer these services with various offers and innovations. With these various offers, consumers also have many choices before deciding to make a purchase. For this reason, this study seeks to find out about the factors that might have an influence on consumer purchase decisions. The factors examined in this study as an independent variable are usability, interaction quality, and information quality. This study took a case study on the Traveloka site, which is one of the sites most often remembered and visited by consumers. Data collection in this study was conducted by survey using a questionnaire. Respondents from this survey were consumers who had purchased an online hotel room booking service at Traveloka. The number of samples in this study were 50 respondents. Data collected was analyzed using regression analysis using SPSS after first being tested for validity, reliability and classical assumption
\end{abstract}

Keyword: Usability, Interaction Quality, Information Quality, Website Quality, Purchase Decision, Online

\begin{abstract}
ABSTRAK
Perkembangan teknologi termasuk internet semakin hari semakin pesat dan berdampak pada perubahan pola bisnis dan juga perilaku konsumen khususnya perilaku konsumen online. Salah satu bisnis yang semakin marak saat ini adalah layanan pemesanan kamar hotel melalui berbagai situs online. Cukup banyak perusahaan online yang menawarkan jasa ini dengan berbagai penawaran dan inovasi masing-masing. Dengan berbagai penawaran ini, konsumen juga memiliki banyak pilihan sebelum memutuskan untuk melakukan pembelian. Untuk itu, penelitian ini berupaya mencari tahu mengenai faktor-faktor yang diperkirakan memiliki pengaruh atas keputusan pembelian yang diambil konsumen. Faktor-faktor yang diteliti pada penelitian ini antara lain kualitas penggunaan, kualitas interaksi, dan kualitas informasi. Penelitian ini mengambil studi kasus pada situs Traveloka yang merupakan salah satu situs yang paling sering diingat dan dikunjungi oleh konsumen. Pengumpulan data pada penelitian ini dilakukan dengan survey menggunakan kuesioner. Responden dari survey ini adalah konsumen yang pernah melakukan transaksi pembelian layanan pemesanan kamar hotel secara online di Traveloka. Jumlah sampel pada penelitian ini adalah sebanyak 50 responden. Data yang dikumpulkan dianalisis menggunakan analisis regresi menggunakan SPSS setelah terlebih dahulu diuji untuk validitas, reliabilitas serta uji asumsi klasik.
\end{abstract}

Kata kunci: Kualitas Penggunaan, Kualitas Interaksi, Kualitas Informasi, Kualitas Website, Keputusan Pembelian, Online

\section{PENDAHULUAN}

Internet sebagai jaringan global yang menghubungkan berbagai pihak melampaui batas Negara, merupakan teknologi yang sudah tidak asing lagi saat ini. Penggunaan internet semakin berkembang pesat. Semula internet hanya dapat digunakan melalui komputer (PC), namun saat ini semakin berkembang dengan adanya teknologi Wi-Fi yang memungkinkan penggunaan internet melalui laptop, tablet, dan telepon genggam. Penggunaan internet memudahkan masyarakat untuk melakukan komunikasi serta memperoleh informasi bahkan dari daerah geografis yang berbeda (Al-Maghrabi dan Dennis, 2011).

Internet sebenarnya sudah dikenal mulai tahun 1969 dan mulai masuk ke Indonesia pada tahun 1988. Internet terus mengalami perkembangan 
sampai dengan saat ini. Pada tahun 1991, jumlah pengguna internet di dunia belum mencapai tiga juga pengguna. Aplikasi e-commerce juga belum dikenal pada tahun tersebut. Hal ini mulai mengalami perubahan semenjak tahun 1999 yang mana jumlah pengguna internet di dunia mencapai angka 250 juta orang dan juga munculnya berbagai bisnis dan transaksi online (Coppel, 2000).

Di Indonesia sendiri, internet sudah digunakan oleh seluruh kalangan baik pemerintah, bisnis, maupun masyarakat umum (Penggunaan Internet Sektor Bisnis, APJII, 2013). Hal ini dibuktikan melalui pertumbuhan pengguna internet yang pesat, kompetisi antar penyelenggara jasa internet (internet service provider) yang semakin ketat dan kompetitif, kecepatan akses yang saat ini sudah mencapai tingkatan $5 \mathrm{G}$ serta pertumbuhan jumlah pemasok dan juga bertambahnya permintaan gadget di pasar.

Berdasarkan informasi dari Kementerian Komunikasi dan Informatika Republik Indonesia, Indonesia menduduki peringkat ke-6 pengguna internet terbesar di dunia. Walaupun memang penetrasi akses internet di Indonesia belum merata dan masih didominasi oleh pengguna di pulau Jawa (berdasarkan data APJII tahun 2017), pengguna internet di Indonesia pada tahun 2017 sudah mencapai 143 juta jiwa. Angka ini meningkat hampir mencapai $350 \%$ jika dibandingkan dengan jumlah pengguna internet di Indonesia pada tahun 2010 yang hanya mencapai 42 juta jiwa (http://www.apjii.or.id/v2/read/page/halamandata/9/statistik)

\section{Gambar 1 Diagram Pengguna Jasa Internet di Indonesia}

\section{Pengguna (Dalam Juta Jiwa)}

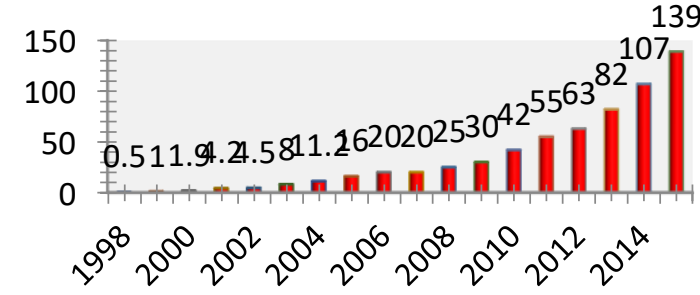

Sumber:

http://www.apjii.or.id/v2/read/page/halamandata/9/statistik.

Pemanfaatan internet saat ini semakin berkembang khususnya sebagai media bisnis secara virtual atau online (e-commerce) yang berfokus pada B2C (business to consumer) (AlMaghrabi dan Dennis, 2011). Situs online memudahkan dan menjadi solusi terkait "entry barrier" karena memudahkan pebisnis untuk mencapai dan mengakses langsung konsumennya di berbagai wilayah dengan biaya yang relatif rendah (Al-Maghrabi dan Dennis, 2011; Chang dan Chen, 2008) yang mana hal ini juga akan berdampak kepada peningkatan daya saing dari bisnis itu sendiri.

Pertumbuhan sektor e-commerce tertinggi di Asia, diperkirakan akan terjadi di Indonesia dengan persentase peningkatan $71,3 \%$ (http://www.marketing.co.id/pertumbuhan-ecommerce-indonesia-tercepat-di-dunia). Hal ini dimungkinkan dengan melihat semakin banyaknya pergeseran pola bisnis dari offline ke online, semakin maraknya mobile wallet, dan juga penjualan berbagai produk maupun jasa secara online. Berdasarkan data dari Badan Koordinasi Penanaman Modal (BKPM), nilai investasi di sektor e-commerce akan mencapai lebih dari US\$ 5 miliar yang menjadikan sektor ini menjadi sektor yang menarik bagi para investor

(https://www.liputan6.com/tekno/read/3230715/ 5-prediksi-tren-e-commerce-di-indonesia-pada2018). 
Salah satu bisnis online yang marak saat ini adalah penjualan berbagai tiket online, baik transportasi, hiburan, tur, maupun hotel. Berdasarkan riset yang dilakukan oleh Nusaresearch (2015) mengenai layanan pemesanan kamar hotel dan tiket pesawat di Indonesia, Traveloka menjadi situs yang paling dominan, diikuti oleh Tiket.com di posisi kedua dan Agoda di posisi ketiga. Berdasarkan hasil survey Nusaresearch tersebut, Traveloka menjadi situs yang paling sering diingat oleh masyarakat, paling sering dikunjungi, dan juga menjadi referensi utama untuk dikunjungi kembali di masa mendatang. Hal ini menarik karena pada awal bisnis dimulai, produk utama dari Traveloka adalah tiket pesawat sedangkan produk utama Agoda adalah voucher hotel. Hal yang diperkirakan dapat mempengaruhi hal ini adalah dari kualitas situs (website). Sebagaimana yang dikemukakan oleh Chincholkar dan Sonwaney (2017), kualitas penggunaan, kualitas informasi, dan interaksi menjadi faktor utama bagi para konsumen dalam melakukan pembelian secara online.

Kualitas penggunaan website mencakup kemudahan untuk dipelajari, mudah digunakan, desain yang menarik, pengalaman yang positif, dan mudah dimengerti. Sedangkan kualitas informasi mencakup hal-hal terkait informasi yang akurat, dapat dipercaya, aktual, relevan, detil, dan disampaikan dalam format yang sesuai dan menarik. Faktor interaksi mencakup reputasi yang baik, keamanan dalam bertransaksi, rasa aman dan percaya dalam memberikan informasi pribadi, menepati janji yang disampaikan, dan rasa komunitas.

Berbagai hal yang telah dikemukakan di atas melatarbelakangi alasan penulis dalam melakukan penelitian mengenai "Pengaruh Kualitas Website terhadap Keputusan Pembelian Layanan Pemesanan Kamar Hotel pada Situs Traveloka". Penelitian ini bertujuan untuk mengetahui pengaruh dari kualitas website terhadap keputusan pembelian layanan pemesanan kamar hotel dengan mengambil studi kasus di situs online Traveloka.

\section{METODOLOGI PENELITIAN Subyek dan Obyek Penelitian}

Pada penelitian ini, yang menjadi subyek penelitian adalah para konsumen yang pernah melakukan transaksi pembelian untuk layanan pemesanan kamar hotel melalui situs Traveloka baik melalui jaringan internet menggunakan komputer ataupun menggunakan peralatan elektronik yang sifatnya mobile. Obyek dari penelitian ini adalah usability, kualitas interaksi, kualitas informasi dan keputusan pembelian.

\section{Sampel Penelitian}

Jumlah sampel yang diambil untuk penelitian ini sebanyak 50 konsumen online yang pernah melakukan pembelian di situs Traveloka untuk layanan pemesanan kamar hotel. Hal ini sesuai dengan literatur yang dikemukakan oleh Roscoe dalam Sekaran dan Bougie (2013) bahwa untuk penelitian multivariat, minimum ukuran sampel yang diambil harus 10 kali dari jumlah variabel yang akan diteliti. Untuk itu, peneliti mengambil sampel sebanyak 50 responden. Untuk metode pengambilan sampel, penulis menggunakan teknik non probability sampling (sampel nonprobabilitas) dengan menggunakan metode convenience sampling.

\section{Metode Pengumpulan Data}

Penelitian ini merupakan causal research (penelitian kausal) dengan menggunakan kuesioner yang menggunakan skala Likert yaitu skala dari 1 sampai dengan 5. Kuesioner disebar pada para konsumen Traveloka yang sudah pernah melakukan pembelian untuk layanan pemesanan kamar hotel. Kuesioner disebarkan baik secara langsung kepada konsumen dan juga secara online.

\section{Uji Validitas dan Reliabilitas}

Daftar pertanyaan (kuesioner) yang akan disebarkan kepada responden harus dipastikan menggunakan alat ukur yang benar dan dapat mengukur variabel penelitian secara konsisten. Oleh karena itu, kuesioner yang disebarkan harus valid dan reliabel. Alat ukur yang digunakan dapat dikatakan valid jika korelasi antara skor dari butir pertanyaan dengan skor total minimal sebesar 0,3. Alat ukur yang digunakan juga dapat dikatakan reliabel jika memiliki nilai Alpha 
melebihi 0,6 dan sangat reliabel jika nilai alpha cronbachnya berada di antara 0,81 sampai dengan 1,00 (Sekaran dan Bougie, 2013). Metode untuk mengukur reliabilitas dari alat ukur yang digunakan, dilakukan dengan menggunakan metode Alpha Cronbach.

\section{HASIL PENELITIAN DAN PEMBAHASAN}

Karakteristik Responden

Responden pada penelitian ini merupakan responden dengan domisili di Jakarta dan Tangerang serta pernah menggunakan Traveloka untuk melakukan pemesanan kamar hotel. Jumlah responden pada penelitian ini adalah sebanyak 50 orang dengan karakteristik sebagai berikut:

Tabel 2. Karakteristik Responden

\begin{tabular}{lcc}
$\begin{array}{l}\text { Karakteristik } \\
\text { Responden }\end{array}$ & $\begin{array}{c}\text { Jumla } \\
\mathrm{h}\end{array}$ & $\begin{array}{c}\text { Persentas } \\
\mathrm{e}\end{array}$ \\
\hline $\begin{array}{c}\text { Jenis Kelamin } \\
\text { Pria }\end{array}$ & 22 & 44.0 \\
\hline Wanita & 28 & 56.0 \\
\hline \multicolumn{2}{l}{ Usia } & \\
\hline $\mathbf{1 7}$ - 25 tahun & 16 & 32.0 \\
\hline 26 - 30 tahun & 12 & 24.0 \\
\hline 30 - 35 tahun & 9 & 18.0 \\
\hline$>$ 35 tahun & 13 & 26.0
\end{tabular}

\begin{tabular}{|c|c|c|}
\hline \multicolumn{3}{|l|}{ Pekerjaan } \\
\hline Pelajar/Mahasiswa & 13 & 26.0 \\
\hline Wirausaha & 14 & 28.0 \\
\hline Karyawan Swasta & 23 & 46.0 \\
\hline \multicolumn{3}{|l|}{ Penghasilan } \\
\hline$<3.000 .000$ & 13 & 26.0 \\
\hline 3.000.000 - 4.999.999 & 5 & 10.0 \\
\hline 5.000 .000 - 6.999.999 & 2 & 4.0 \\
\hline
\end{tabular}

\begin{tabular}{|ccc|}
\hline $\mathbf{7 . 0 0 0 . 0 0 0} \boldsymbol{- ~ 8 . 9 9 9 . 9 9 9}$ & 20 & 40.0 \\
\hline $\mathbf{>} 9.000 .000$ & 10 & 20.0 \\
\hline
\end{tabular}

Sumber: Hasil pengolahan data

\section{Uji Validitas dan Reliabilitas}

Untuk mengukur validitas dan reliabilitas dari kuesioner, digunakan metode Alpha Cronbach. Berdasarkan hasil dari pengolahan data menggunakan software SPSS, dapat disimpulkan bahwa alat ukur yang digunakan valid dan reliabel yang mana nilai dari Alpha untuk usability, interaksi, informasi dan pembelian, kesemuanya lebih besar dari 0,6.

Tabel 3. Reliabilitas Variabel

\begin{tabular}{ccc}
\hline Variabel & $\begin{array}{c}\text { Nilai Cronbach } \\
\text { Alpha }\end{array}$ & $\begin{array}{c}\text { Jumlah } \\
\text { Indikator }\end{array}$ \\
\hline Usability & 0,604 & 8 \\
\hline Interaksi & 0,917 & 7 \\
\hline Informasi & 0,855 & 7 \\
\hline Pembelian & 0,787 & 5 \\
\hline
\end{tabular}

Sumber: Hasil pengolahan data

\section{Uji Asumsi Klasik}

Pengujian terkait asumsi klasik yang terdiri dari uji multikolinieritas, uji autokorelasi, uji heteroskedastisitas, dan uji normalitas menunjukkan bahwa data terdistribusi secara normal. Multikolinieritas tidak terjadi, hal ini disimpulkan berdasarkan hasil dari VIF $<10$ dan Tolerance $>0,1$. Selain itu data juga tersebar, tidak membentuk pola tertentu.

\section{Uji Hipotesis Parsial}

Berikut adalah hasil pengolahan data untuk analisis regresi berganda. Pengolahan data dilakukan menggunakan SPSS.

Tabel 4. Hasil Uji t

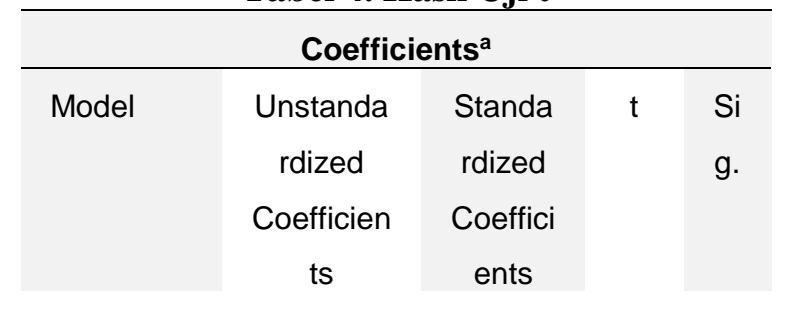




\begin{tabular}{|c|c|c|c|c|c|c|}
\hline & & B & $\begin{array}{l}\text { St } \\
\text { d. } \\
\text { Er } \\
\text { ror }\end{array}$ & Beta & & \\
\hline \multirow[t]{12}{*}{1} & (Con & - & .3 & & - & .3 \\
\hline & stant) & .3 & 51 & & .9 & 5 \\
\hline & & 25 & & & 26 & 9 \\
\hline & Usabi & .2 & .0 & .187 & 3. & .0 \\
\hline & lity & 67 & 82 & & 26 & 0 \\
\hline & & & & & 9 & 2 \\
\hline & Infor & .5 & .0 & .539 & 9. & .0 \\
\hline & masi & 66 & 61 & & 29 & 0 \\
\hline & & & & & 3 & 0 \\
\hline & Intera & .2 & .0 & .451 & 7. & .0 \\
\hline & ksi & 70 & 34 & & 81 & 0 \\
\hline & & & & & 3 & 0 \\
\hline
\end{tabular}

a. Dependent Variable: Pembelian

Sumber: Hasil pengolahan data

Berdasarkan hasil pengujian di atas (parsial), dapat disimpulkan bahwa ketiga variabel (usability, interaksi, dan informasi) secara parsial, masing-masing memiliki pengaruh yang signifikan (sig $<0,05)$ terhadap keputusan pembelian layanan pemesanan kamar hotel di Traveloka.

\section{Uji Hipotesis Simultan}

Berikut adalah hasil pengolahan data untuk mengetahui hasil uji seluruh variabel bebas secara simultan terhadap variabel terikat.

Tabel 5. Hasil Uji ANOVA

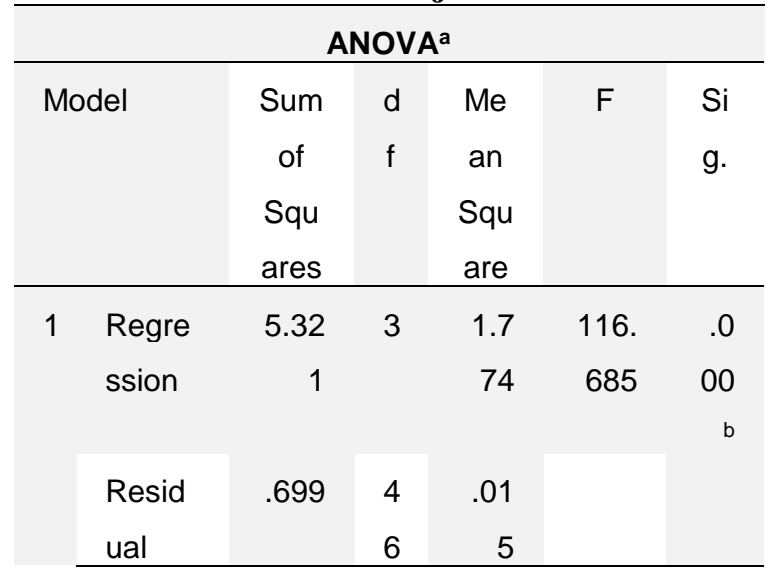

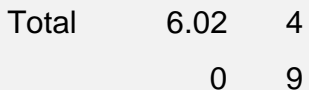

a. Dependent Variable: Pembelian

b. Predictors: (Constant), Interaksi, Usability,

Informasi

Sumber: Hasil pengolahan data

Berdasarkan hasil pengujian di atas, dapat dilihat bahwa seluruh variabel bebas secara simultan memiliki pengaruh terhadap keputusan pembelian layanan pemesanan kamar hotel di Traveloka $($ sig < 0,05$)$.

\section{Koefisien Determinasi}

Berikut adalah nilai koefisien determinasi yang diperoleh pada penelitian ini:

Tabel 6. Hasil Koefisien Determinasi

\begin{tabular}{|c|c|c|c|c|}
\hline \multicolumn{5}{|c|}{ Model Summary } \\
\hline $\begin{array}{l}\text { Mod } \\
\text { el }\end{array}$ & $\mathrm{R}$ & $\begin{array}{c}\text { R } \\
\text { Squar } \\
\text { e }\end{array}$ & $\begin{array}{c}\text { Adjuste } \\
\text { d R } \\
\text { Square }\end{array}$ & $\begin{array}{l}\text { Std. } \\
\text { Error of } \\
\text { the } \\
\text { Estimat } \\
\text { e }\end{array}$ \\
\hline 1 & $\begin{array}{r}.940 \\
\mathrm{a}\end{array}$ & .884 & .876 & 12329 \\
\hline
\end{tabular}

a. Predictors: (Constant), Interaksi, Usability, Informasi

Sumber: Hasil pengolahan data

Berdasarkan hasil yang diperoleh pada tabel di atas, dapat disimpulkan bahwa ketiga variabel bebas (usability, interaksi, dan informasi) memiliki pengaruh terhadap keputusan pembelian layanan pemesanan kamar hotel di Traveloka sebesar $88,4 \%$, sedangkan sisanya sebesar $11,6 \%$ dipengaruhi oleh variabel lain.

\section{SIMPULAN}

Berdasarkan hasil pengolahan data di atas, ketiga variabel bebas (usability, interaksi, dan informasi) memiliki pengaruh terhadap variabel terikat yaitu keputusan pembelian layanan pemesanan kamar hotel di Traveloka baik secara parsial maupun simultan. Kontribusi dari ketiga 
variabel bebas terhadap variabel terikat dapat dikatakan sangat besar yaitu sebesar $88,4 \%$.

\section{DAFTAR PUSTAKA}

Al-Maghrabi, Talal, dan Dennis, Charles. (2011). What drives consumers' continuance intention to e-shopping? International Journal of Retail \& Distribution Management, vol. 39, no. 12, pg. 899-926.

Asosiasi Penyelenggara Jasa Internet Indonesia dan Badan Pusat Statistik. (2013). Penggunaan Internet Sektor Bisnis.

Barnes, S. J. \&. Vidgen, R. T. (2000). WebQual : An Exploration of Website Quality. In: Proceedings of the eight European Conference of Information Systems, Vienna Austria, pg. 298-305.

Barnes, S., dan Vidge, R. (2002) An Integrative Approach To The Assesment Of ECommerce Quality. Journal Of Electronic Commerce Research Vol.3 No.3.

Chang, Hsin Hsin, dan Chen, Su Wen. (2008). The impact of online store environment cues on purchase intention. Online Information Review, vol. 32, no. 6, pg. 818-841.

Chincolkar, Snehal \& Sonwaney, Vandana. (2017). Website Attributes and its Impact on Online Consumer Buying Behaviour: An Empirical Study of Online Consumers in Mumbai Region. Indian Journal of Science and Technology, vol. 10, no. 47, pg. 1-9.

Coppel, J. (2000). E-commerce: impacts and policy challenges. OECD Economics Department Working Papers, no. 252, OECD Publishing, Paris.

Curty, R. G., \& Zhang, P. (2013). Website features that gave rise to social commerce: a historical analysis. Electronic Commerce Research and Applications, vol. 12, no. 4, pg. 260-279.
Dellarocas, C. (2006). Strategic Manipulation of Internet Opinion Forums: Implications for Consumers and Firms. Managemeng Science, vol. 52, no. 10, pg. 1577-1593.

Ebert, Ronald J. dan Griffin, Ricky W. (2009). Business Essentials. Seventh Edition. Pearson : New Jersey

Ghafiki, Rafdi dan Setyorini, Retno. (2017). Pengaruh Kualitas Website terhadap Keputusan Pembelian pada Situs Bukalapak.com. e-Proceeding of Management : Vol.4, No.1 April 2017, pg. 678-686

Konradt, U., Lückel, L., \& Ellwart, T. (2012).The role of usability in business-to-business ecommercesystems: Predictors and its impact on user's strainand commercial transactions. Advances in HumanComputer Interaction.

Kotler, Philip dan Armstrong, Gary. (2010). Principles of Marketing. Thirteen Edition. Pearson : New Jersey.

Kotler, Philip and Gary Armstrong. (2012). Marketing Management Edisi 13. Pearson : New Jersey.

Kotler, Philip et.al. (2012). Principles of Marketing: An Asian Perspective. Pearson : Singapore

Kurniawan, Rizky; Kusumawati, Andriani; dan Priambada, Swasta (2018). Pengaruh Kualitas Website (Webqual 4.0) terhadap Kepercayaan dan Dampaknya pada Keputusan Pembelian pada Website ECommerce (Studi pada Konsumen PT. B). Jurnal Administrasi Bisnis (JAB)|Vol. 62 No. 1 September 2018, 198-206

Laudon, Kenneth C. dan Traver, Carol Guercio. (2012). E-commerce 2012: business, technology, society. Pearson: England. 
Nielsen, J., Molich, R., Snyder, C., \& Farrell, S. (2001). E-Commerce user experience. Fremont, CA:Nielsen Norman Group

Oz, Effy. (2002). Foundation of e-Commerce. Pearson Education Inc. : New Jersey.

Park, Chung-Hoon and Young-Gul Kim (2003). Identifying keyfactors affecting consumer purchase behavior in an online shopping context. International Journal of Retail and Distribution Management, vol. 3, no. 1, pg. 16-29.

Peter, J. \& Olson, J. C. (2013). Olson. Perilaku Konsumen dan Strategi Pemasaran. Diterjemahkan oleh Dian Tantri Dwiandani. ed. 9 jd. 1. Jakarta: Salemba Empat

Sekaran, Uma \& Bougie, Roger. (2013). Research Methods for Business. United Kingdom: John Wiley \& Sons Ltd.

Trusov, M. et. al. (2009). Effects of word of mouth versus traditional marketing: findings from an internet social networking site. Journal of Marketing, vol. 73, no. 5, pg. 90102.

Turban, Efraim dan Volonino, Linda. (2012). Information Technology for management. USA: John Wiley \& Sons.

Wang, C., \& Zhang, P. (2012). The evolution of social commerce: An examination from the people, business, technology, and information perspective. Communication of the Association for Information Systems, vol. 31, no. 5, pg. 105-127.

Yadav, M.S., de Valck, K., Hennig-Thurau, T., Hoffman, D.L., \& Spann, M. (2013). Social commerce: Acontingency framework for assessing marketing potential. Journal of Interactive Marketing, vol. 27, pg 311-323.

\section{Online}

http://www.apjii.or.id/v2/read/page/halamandata/9/statistik http://www.marketing.co.id/pertumbuhan-ecommerce-indonesia-tercepat-di-dunia https://www.liputan6.com/tekno/read/3230715/5 -prediksi-tren-e-commerce-di-indonesia-pada2018 